\title{
Understanding urban flood vulnerability and resilience: a case study of Kuantan, Pahang, Malaysia
}

\author{
M. Y. Safiah Yusmah ${ }^{1}$ (D) L. J. Bracken ${ }^{2}$ (D) Z Z. Sahdan ${ }^{3} \cdot$ H. Norhaslina' . \\ M. D. Melasutra ${ }^{4}$ A. Ghaffarianhoseini ${ }^{1}$ - S. Sumiliana ${ }^{5}$ - A. S. Shereen Farisha ${ }^{1}$
}

Received: 2 November 2018 / Accepted: 17 February 2020 / Published online: 14 March 2020

(c) The Author(s) 2020

\begin{abstract}
Malaysia is frequently affected by the annual flooding event caused by the seasonal monsoon which accounts for significant losses. Flood risk, exposure and damage potential are increasing, causing the level of poverty and vulnerability to rise. The annual occurrence of the flood hazard has forced residents to prepare beforehand to help them spring back to their daily life faster. This study aimed to investigate and understand the vulnerability and resilience of the victims towards floods in Kuantan, Pahang. A qualitative approach of focus group discussion (FGD) is used to obtain detailed and authentic information. A total of thirty-one (31) participants who were flood victims took part in the FGD. Six groups were formed for the FGD based on different criteria such as gender, age, education background, occupation, monthly income and social class. Each FGD group consisted of four to six participants. When the participants were asked to rank their top five daily challenges, many thought that flooding is not a threat compared to food, because flooding occurs annually and is predictable. The results showed that the participants are well aware of the causes of the vulnerability faced by them due to the flooding event. Reasons highlighted from the results for the flood occurrence are the demography of the area, the location of the houses, the improper and inaccurate information and evacuation plan, the management of the transit centre and the lack of preparation by the community. The participants also thought that poor dissemination of early warning information and flood control infrastructures from the government and other related agencies caused the victims to have insufficient time to prepare for emergencies, hence causing the recovery process to be slower. However, from their hands-on experiences, they were able to put forward suggestions on the resilience towards flood for future references.
\end{abstract}

Keywords Vulnerability $\cdot$ Resilience $\cdot$ FGD $\cdot$ Urban flooding $\cdot$ Pahang $\cdot$ Malaysia

M. Y. Safiah Yusmah

dr.safiah@um.edu.my

Extended author information available on the last page of the article 


\section{Introduction}

The rapidly changing climate threatens to increase natural hazards and extreme weather such as floods, cyclones, hurricanes and drought, with floods being the most disastrous, frequent and widespread (Dhar and Nandargi 2003). Hydro-meteorological themed disaster has increased around Asia and South-East Asia countries over the last two decades. Countries such as China, India, Bangladesh and Pakistan are known as the supermarket for disaster especially in terms of disastrous floods (James 2008). Therefore, due to the global climate change, middle and rapidly developing countries are the victim of the economy as most of the damage caused by the disastrous events occur in poor countries with few assets. The occurrence of flooding are predicted to quadruple by 2080 as sea level is expected to continue rise due to global climate change (Small and Nicholls 2004). This is especially frightening for the population living in coastal areas as it is the most populated area in most countries with an estimate of $23 \%$ of world population living within $100 \mathrm{~km}$ and less than $100 \mathrm{~m}$ above sea level (Molua and Lambi 2007; Small and Nicholls 2004). Urban flooding is well known as it has caused damage and loss of life. Urban flooding inundates land or property in a built environment, particularly in densely populated areas. These floods are usually caused by flash floods, coastal floods or river floods, but urban flooding is often specifically due to poor drainage in urban areas. Urban flooding is often related to global climate change issues because most urban areas are the major contributors to greenhouse gas (GHG) emissions that eventually causes global warming. Over concentrated population, increasing infrastructure and economy cause the sustainability of an urban area to worsen. Over time it has become more challenging for the government and developers to create development plan that balances the demand of urbanization while minimizing the use of natural resources. Urban planners should concern and practice actions against climate-induced disasters (Godschalk 2003; Saavedra and Budd 2009; Kithia and Dowling 2010).

Malaysia, as a South-East Asia country, is located near the equator with climate categorized as equatorial. Equatorial climate is relatively hot and super-humid throughout the year with average rainfall of $250 \mathrm{~cm}$ annually (DID, 2007). In addition, it is essential to learn that the climates in Peninsular Malaysia differ to East Malaysia where the climate in West Malaysia is directly influenced by the monsoon wind from the northeast and southwest, while in East Malaysia the climate is mostly influenced by maritime weather. A yearly constant cycle of heavy rainfall at the east coast of Peninsular Malaysia and east of Malaysia (Sabah and Sarawak) between November and February are caused by the northeast monsoon wind while rain bearing winds from April to September caused by the southwest monsoon. The amount of rain from the southwest monsoon is lesser than the northeast monsoon that can reach up to $660 \mathrm{~mm}$ in $24 \mathrm{~h}$. Annually, the average rainfall in Peninsular Malaysia can reach up to $2420 \mathrm{~mm}$, while in Sabah and Sarawak, the amount of rainfall is more than the Peninsular with $2630 \mathrm{~mm}$ for Sabah and $3830 \mathrm{~mm}$ for Sarawak (DID 2007). According to Chia (1971), there are two types of rainfalls that cause the flood. They are (1) moderate intensity, long duration rainfall at a wide area and (2) high intensity, short duration localized rainfall. The occurrence of floods in Malaysia can be predicted. Usually, east coast and eastern Malaysia were affected by floods during December to January as the northeast monsoon sweeps, while the west coast of Peninsular is mainly affected in September to November with thunderstorms due to the inter-monsoon period. Generally, in Malaysia, most floods occur due 
to continuous heavy rainfalls that result in runoff due to the excess of water supplies that surpass the capacities of streams and rivers.

Several major flood events have occurred in Malaysia over the last few decades. For example, a gale force wind period in 1886 caused severe flooding in Kelantan. In 1926, the worst floods in Peninsular Malaysia caused scares among the people as it caused widespread damage to property, mental, physical, infrastructure and agriculture. After the initial days of the flood, projected losses to local business in and around the Klang River valley were estimated at around $\$ 12,000$ Straits dollars. Even for those who did not suffer major flood damage, all businesses lost several day's trade as the city stood at standstill. In Pahang, a private railway linking the plantation to mines at Sungei Lembing was partially washed away and trains had to be dug out of the mud afterwards (Williamson 2016). Flooding has become a significant yearly event occurrence in Malaysia especially at the end of the year. Most of the flood-prone areas can be found in several states in Peninsular Malaysia such as Kelantan, Johor, Pahang, Perak, Kuala Lumpur and Selangor while for east Malaysia it is Sabah and Sarawak (DID 2007). Most of the states in Malaysia are prone to flood risk due to (1) the natural physical topography and drainage, and (2) human geography of settlement and land use. Malaysia in the past is mostly riverine people that choose to inhabit banks and floodplain of the major river such as Pahang river, where most of the settlement is indeed high in flood risk (Chan 2012). Most of the floods occur due to the monsoon rainfall and intense rain storms. However, in recent decades, the cause of flood is not only due to natural events; the frequent occurrence of flash flood in cities such as Kuala Lumpur, Selangor and Kelantan was caused by poor drainage and area where rapid urbanization takes place. Chia (1971) stated several sources that cause flooding in Malaysia, loss of flood storage results from development that extend towards floodplain areas, the increase and rapid urbanisation that cause the rate of runoff to increases, faulty drainage system by the locals and continuous heavy rainfalls that cause the water storage to exceed the capacity of the river.

The annually frequent flood that occurs in Malaysia has taken a toll on the socio-economy in terms of flood damages. The flood damage is on the rise due to the increase in flood risks such as the urban development on flood plain area of major rivers. The damages and the losses caused by the flood can be direct or indirect, where direct flood damage is due to the contact of flood water with the building while indirect flood damage causes loss of work and production that eventually cause the victim to develop stress and suffering (Green et al. 1988). The estimated amount of damages due to the flooding is superior in compact and high densities urban areas compared to rural areas. According to Chan (1997), the chance of extreme flood damage occurrence is high in large urban centers such as Kuala Lumpur and Georgetown, Pulau Pinang. Moreover, aside from damages towards the economy, the flood may give permanent aftermath towards mental health and death. It is not unusual for the flood victims to suffer from trauma and mental health for the rest of their lives. Usually, those with a fragile mental state are more susceptible to mental collapse when they were engaged to the unwonted and wicked situation or events. Women and children are the group of people that easily suffer in a critical event. According to Jamaluddin (1985), to abate post-traumatic events, the victims themselves need to concur the situation in a more positive and appropriate ways for a chance of quick recovery.

Following the annual flooding event occurrence in Malaysia, the government (including the Drainage and Irrigation Department (DID)) has carried out several positive actions to mitigate the flood problem. These consist of structural measures and non-structural measures (Chan 2015). Structural measures focus more on how banks and embankments play their role in controlling flood flows. Example of structural measures taken by the 
government is the Storm Water Management and Road Tunnel (SMART) in Kuala Lumpur to alleviate flash flood problems that occur when heavy rainfalls hit Kuala Lumpur (Umar 2007). An example of non-structural measures relates land use planning and flood forecasting and warning systems to mitigate the impact of flooding, such as the flood forecasting and warning system (DID 1988). Most of the flood mitigation projects and actions undertaken by the government were structural measures such as canalization of rivers, raising river embankments and the building of a multi-purpose dam. Yet, the government has been upgrading the Flood Forecasting and Warning System for early warning. This infrastructure had been installed all over Malaysia with 233 telemetric rainfall stations, 190 telemetric water level stations, 256 manual stick gauges, 84 flood warning boards, 217 flood sirens and 9 real-time flood forecasting and warning system in 9 river basins (DID 2007). The DID has also taken an initiative to established an Internet-based National Flood Monitoring System (http://infobanjir.moa.my) where all the data on rainfall and water level can be accessed by the public. In brief, the flood management activities attempted by the government of Malaysia are (1) the National Resource Study, (2) Development of infrastructure for flood forecasting and warning system, (3) National Flood Monitoring System, (4) Flood Watch and (5) Urban Storm Water Management Manual for Malaysia (Hussaini 2007).

Vulnerability and resilience act as a leading tool to quantify and map human aftermath from hazards. In the context of social-ecological systems, resilience refers to the magnitude of disturbance that can be absorbed before a system changes to a radically different state as well as the capacity to self-organize and the capacity for adaptation to emerging circumstances (e.g., Carpenter et al. 2001; Berkes et al. 2003; Folke 2006). Vulnerability, by contrast, is usually portrayed in negative terms as the susceptibility to be harmed. The central idea of the often-cited IPCC definition (McCarthy et al. 2001) is that vulnerability is the degree to which a system is susceptible to and is unable to cope with adverse effects (of climate change). According to Proag (2014) vulnerability is defined as a measure of hazard that compliance with physical, economy and social and the implication that results in the ability to cope with the event occurrence. While the concept of resilience itself has taken two broad forms of (1) hard resilience and (2) soft resilience (Moench 2009) where hard resilience is a direct strength when placed under pressure and soft strength is the ability to absorb and recover from the impact of destructive event (Rufat et al. 2015). According to Balica and Wright (2010), resilience is the ability of a system to handle commotions while maintaining the efficiency in social, economic, physical and environment. It is in the nature of human being to become vulnerable when their normal daily activities, facilities and consumption were affected in critical factor from the disaster. Moreover, the demographic characteristic, socioeconomic status and health is the leading driver of vulnerability due to flooding events. Resilience is a system that functions to work in a certain way under normal circumstances. Therefore, resilience is important in several sectors such as technical, political, environment, ecology, economy, legal and in an organization. Variables that usually concerned in measuring the degree and magnitude of vulnerability and resilience from disastrous events is employment, income, health and educational status. Jackson (2006) stated that resilience, vulnerability and adaptive capacity are interrelated with each other when it comes to natural disaster events. Not only that, it also stated that a community with low vulnerability has the potential to have high resilience. Several other definitions of resilience can be found in Table 1. Vulnerability deals more with the environmental risk and hazards while for resilience, it deals more with the change and persistence of an ecosystem (Carpenter et al. 2001; Gunderson 2000). Furthermore, in flood-prone rural areas, the norms of poverty have heightened 


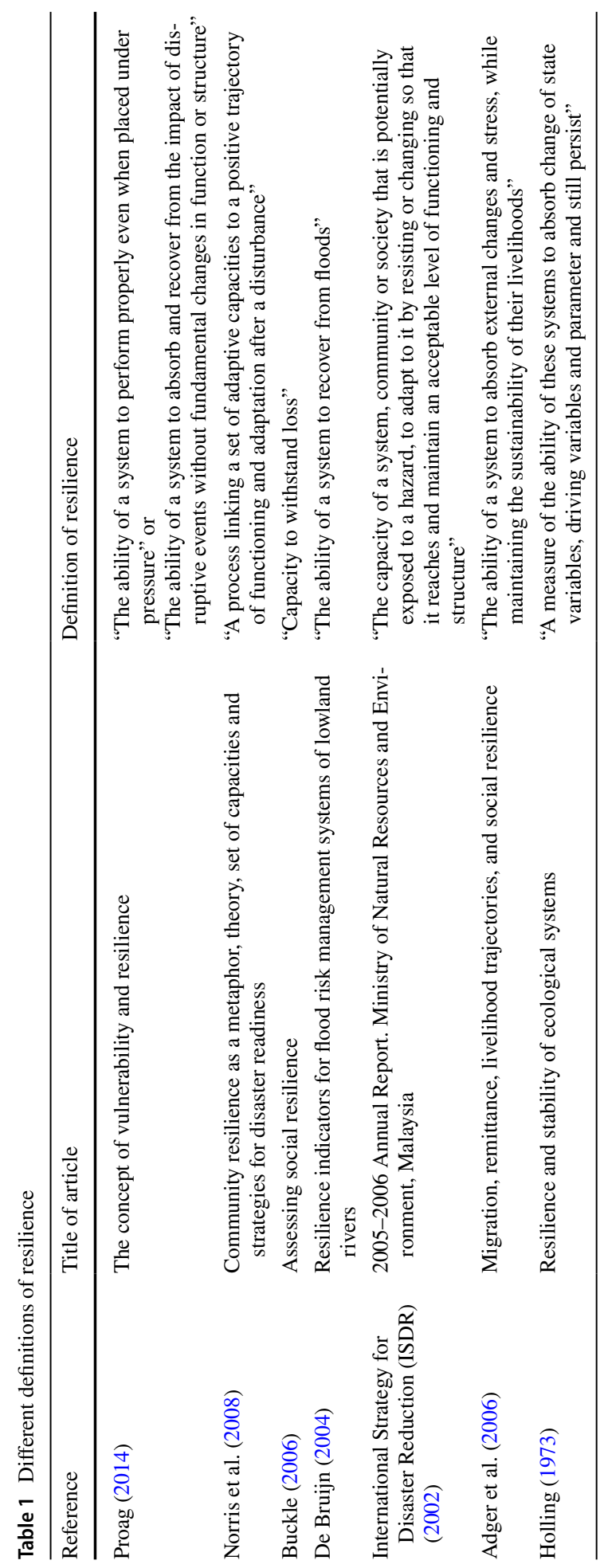


vulnerability among the poor while in the urban area, the vulnerability is much lower compared to the rural area as more strategies, planning, investment and development were undertaken to curb the problem (resilience). In short, the poor suffer more from hazards compared to the wealthy, although poverty and vulnerability are not always related or in line with each other (Chan and Parker 1996). The vulnerability experienced by the poor was due to the lack of opportunity and access to structures of power where knowledge and resources of the hazard or disaster were limited. In addition, aside from the poor, vulnerability is familiar among the lower income groups, Malaysia is dominated by the Bumiputera communities where fatalities were common while low-level vulnerability can be expected in the urban settlement where it is mostly populated by the Chinese and Indians. This is because, back in the past before the Chinese and Indians ethnics populated Malaysia, the Bumiputera that originated from the Peninsular choose to settle in the area near the coastal and major rivers where they can have easy access to food and transportation. Resilience actions need to cultivate and be implemented in order to prevent damages and loss of life. This needs to be one of the main purposes of development rather than a characteristic of a good development (Bene et al. 2012). Resilience needs to be applied in urbanization process as urban areas were known to be complicated social ecological systems (Simon 2007; Swyngedouw and Heynen 2003).

The aim of this paper is to investigate the perceptive of the urban community on the vulnerability of flood. Next, this paper studies on the various suggestion from the local community on future resilience towards flood event. A method of focus group discussion (FGD) was applied in order to obtained detail and compact information from the stakeholder in a different category of people or group of people. From the results, it showed that the urban community was aware of the cause of the vulnerability in their neighbourhood towards the flood event. The data obtained from the FGD were solely from the real-life experience of the stakeholder that were involved in the group discussion. From the discussion, various suggestions have been put forward by the stakeholder on their future resilience actions towards flooding.

\section{Materials and method}

Information regarding the urban flooding situation and experiences was collected through the qualitative method known as focus group discussions (FGD) that consists of structured discussion that are usually used to obtain in-depth information from a group of people about a specific topic. The group discussion was engaged by the flooding victims themselves; therefore information regarding sensitive topics can be obtained. The district of Kuantan which is located in the state of Pahang was selected as the study area due to the lack of research done in the state compared to other floodprone states such as Selangor and Kelantan. In this study, the researchers were interested in the vulnerability faced by the flooding victims, annually, in the district of Kuantan and the local resilience measures taken to minimize the natural disasters. 


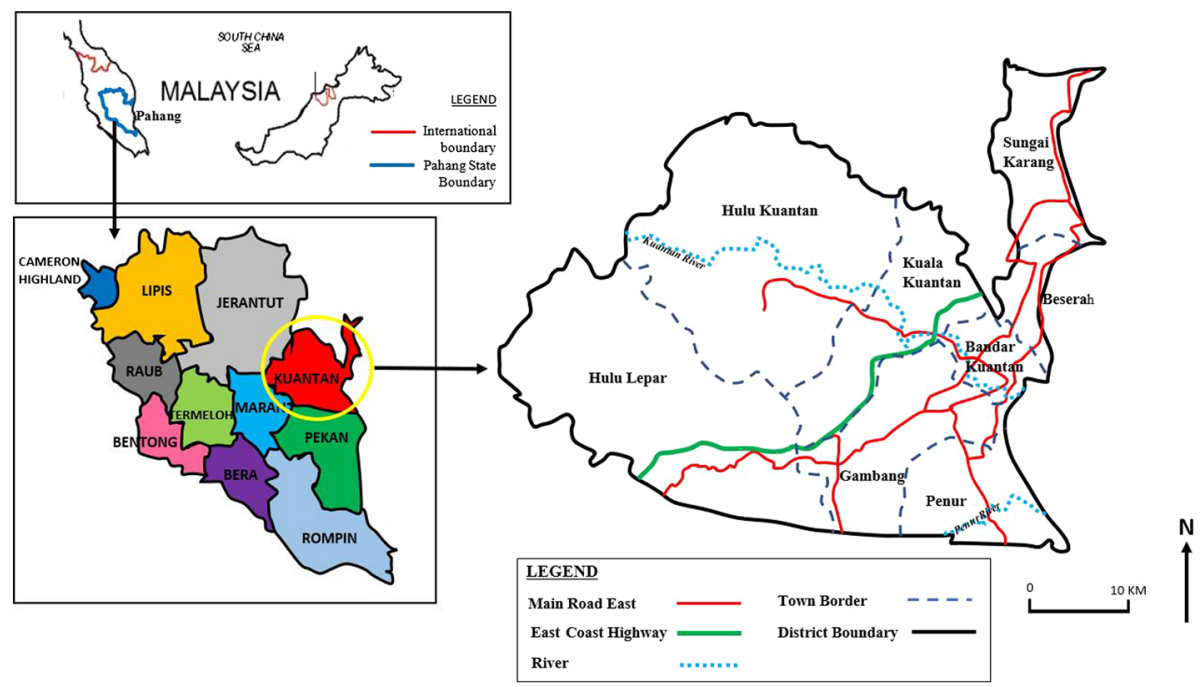

Fig. 1 The study area

\subsection{Study area}

Figure 1 shows a map of Kuantan, Pahang, Malaysia. The district of Kuantan is situated in the state of Pahang. Pahang is the third largest state in Malaysia after Sarawak and Sabah. Geographically, Pahang is the biggest state in Peninsular Malaysia and has the longest river in Peninsular Malaysia at $459 \mathrm{~km}$. Since Peninsular Malaysia is affected by two monsoons (northeast and southwest monsoon) and two inter monsoons (Suhaila et al. 2010), the Pahang Basin receives a high total of rainfall during the northeast monsoon period that contributes and causes flooding events along the river in the basin (DID 2005). Other main sources of flooding in the basin are the extreme increase in river discharge due to the monsoon and the sea waves from the South China Sea. The overflow water results in floods within the basin area which occur yearly, particularly from November to December (Lun et al. 2010). Kuantan has a total area of $2453 \mathrm{~km}^{2}$ and is situated $250 \mathrm{~km}$ east from Kuala Lumpur. The monsoon that brought the heavy rainfall in November to December every year is 2.3 times higher than the normal average rainfall. The Kuantan River Basin (KRB) is an important watershed of Kuantan city. The basin starts from Sungai Lembing, passing through Kuantan and finally drains to the South China Sea. Heavy rainfall causes spill over of rivers and flooding in low areas that encompass human activities, both social and economic. In December 2001 to January 2002, Kuantan experienced a massive flood caused by continuous heavy rainfall during the northeast monsoon. Most of the city area was submerged under water when nearby rivers overflowed. This incident affected 18,000 people and $22.94 \mathrm{~km}^{2}$ of land (EKA 2002). Another dreadful flood condition and incident occurred 10 years after the massive flood happened in 2001/2002; an unexpected flood due to continuous rainfall that caused 6000 victims to lose property and assets. Due to the poor drainage system in Kuantan, the intercity roads that connect people from city to city were badly flooded causing hundreds of vehicles to be trapped. The recent flood occurrence in 2013 was caused by the prolonged heavy rainfall, high tides and rapid urbanization process. More development was undertaken in the low-lying area that are easily flooded. The 
2013 flood in Kuantan caused 14,044 people to be evacuated from their houses. Furthermore, the flood resulted in major damages towards basic facilities such as electricity, road structures, buildings and personal belongings. These have cost a fortune for the government to repair the damages done by the flood hazard (Jamaludin et al. 2013). Aside from heavy rainfall caused by the northeast monsoon, the occurrence of flooding in Kuantan can be due to the rise in temperature that causes heavy rainfall and rise in sea level.

\subsection{Participants}

The victims of the flooding hazard were identified in the study area. A total of 31 participants joined the focus group discussion. This method was applied to conceptualize the relationship between vulnerability and resilience of the urban community from people with different backgrounds. Six focus group discussions (FGDs) were formed during this study. The groups were formed to discuss the urban flood vulnerability and resilience based on different criteria of gender, age, education background, occupation, monthly income and social class. Each of the FGD group consisted of four to six participants from various backgrounds. The list of FGD participant for each group is shown in Table 2 which highlights differences in the number of participants in each group due to the difficulty in getting participants despite earlier preparations. Most of the participants involved were selected from the haphazard settlement around Kuantan River, Isap River, Belat River, Pandan River and Galing River. The discussion was participated by the flooding victims with age range from 16 to 69 years old. A wide range of ages helped in widening the answer and opinion on the highlighted issues in the group discussion due to differences in generations and ways of thinking. The group discussion was participated in 16 females and 15 males.

\subsection{Data collection}

Data collection was carried out in March 2016. Qualitative data collection method was applied to extract ground information on the relationship between vulnerability and resilience of the urban community from different background. The two-qualitative method applied was the focus group discussion (FGD) and field observation. In this study, the semi-conducted interview was the main approach for data collection. FGD is a qualitative method that has been defined as a discussion that has been carefully designed to gain or gather impressions or viewpoints on a defined circle of interest in a non-threatening environment (Kruger 1994). Moreover, the group discussion, focuses on perceptions, opinions and the motives underlying their acts and behaviour (Greenbaum 2000; Hyden and Bulow 2003; Maykut and Morehouse 1994). This method was chosen for the study because it is particularly useful for exploring people's or the victim's experience and knowledge (Kitzinger 1995).

An informed consent agreement was obtained from those who agreed to take part in the discussion, and a suitable time for the discussion was agreed. All the participants in the group discussion were asked to describe their various experiences. At the beginning of each focus group session a moderator introduced themselves and gave a brief explanation about the procedures of the discussion to the participants. Besides conducting the discussion in the group, the moderator helped the participants to focus on the topic discussed. Each focus group session was conducted for no longer than $45 \mathrm{~min}$. The key questions prepared earlier for the moderator to discuss with their respective group are shown in Fig. 2. 
Table 2 List of FGD participants

\begin{tabular}{|c|c|c|c|}
\hline Group & Criteria & Participants & $\begin{array}{l}\text { Total par- } \\
\text { ticipants }\end{array}$ \\
\hline 1 & Age & $\begin{array}{l}16 \\
28 \\
35 \\
42 \\
60 \\
62\end{array}$ & 6 \\
\hline 2 & Education & $\begin{array}{l}\text { School } \\
\text { School } \\
\text { School } \\
\text { College }\end{array}$ & 4 \\
\hline 3 & Social Status & $\begin{array}{l}\text { Resident } \\
\text { Politician } \\
\text { Society } \\
\text { NGO } \\
\text { Religious }\end{array}$ & 5 \\
\hline 4 & Gender & $\begin{array}{l}\text { Male } \\
\text { Male } \\
\text { Male } \\
\text { Female } \\
\text { Female } \\
\text { Female }\end{array}$ & 6 \\
\hline 5 & Occupation & $\begin{array}{l}\text { Self Employed } \\
\text { Self Employed } \\
\text { Government } \\
\text { Government } \\
\text { Private }\end{array}$ & 5 \\
\hline 6 & Income & $\begin{array}{l}<1000 \\
<1000 \\
<1000 \\
1001-3000 \\
1001-3000\end{array}$ & 5 \\
\hline \multicolumn{2}{|c|}{ Total FGD participants } & & 31 \\
\hline
\end{tabular}

All of the conversations that occurred in the discussion group were recorded on video for further analysis.

\subsection{Data analysis}

The FGD was video recorded and later analysed using qualitative inductive content analysis, also known as qualitative data analysis. The analysis was carried out in several steps which involved coding, whereby raw data were raised to conceptual level. It is pertinent to analyse data for context as it involves identifying conditions, nature of the situation, circumstances or problems from the participants response. This study analysed the qualitative data by utilizing 
1. Were you affected by the flood that happened in the end of December 2014? How were you affected?

2. Was this your first experience? Can you tell us how it happened?

3. If it was not your first experience, how many times have you experienced it and tell us about them?

4. What is your opinion on where and who were most affected? How bad were they affected? Tell us about the loss.

5. Have you anticipated that the flood was going to happen? What was your preparation before it happened?

6. What actions have you taken before, during and after the disaster?

7. In your opinion, are your house, your neighbourhood, your town and your city are safe from future flood (Garai, 2016)events? Have you thought of moving to another place that is safe from flood and sell your house?

8. Were there any mitigation/rehabilitation program planned and implemented to avoid flood from recurring? Who were involved? Are they effective?

9. How long did the city recover from the flood event and who had taken the responsibility?

10. In your opinion, is the rehabilitation program sufficient? Is there anything else that can be done to increase resilience for flooding?

11. If flood is expected to happen again in future, even after the resilience program, who do you think will still be affected? Why?

12. Did you receive any flood warnings? From who?

13. Rank the following 5 top daily life challenges according to your priority:
a. Economy
b. Children's education
c. Food
d. Health
e. Flood

Fig. 2 FGD key questions

computer-aided software or computer-aided qualitative data software (CAQDAS), Atlas.ti. Atlas.ti is known for its capability in workbench for qualitative data analysis particularly for audio data. This software analysed and interpreted text and audio using coding and annotating activities. For analysing, the video and audio data were transcribed into word processing documents. Every word, sentence and paragraph needed to be analysed attentively for further interpretation of the data. Therefore, it is important to organize, reduce and describe the data delicately in order to avoid unnecessary mistakes that will affect the results produced. According to Schwandt (1997), the analysis must be done in a rigorous, systematic, disciplined and imitative manner with the documented methodology. Thereupon, to analyse simply means to break down the data into coding (Miles and Huberman 1994) and categories (Dey 1993). Initial coding using CAQDAS is time-consuming to ensure that the building of the codes is systematic. As the data are broken up for classification, it is then developed into a concept where connections are made between them to enable new descriptions to be made. Next, once the data were classified, they were checked for regularities, variation and peculiarities in patterns. This helps in identifying potential connections by data linking and associations among the categories. All in all, the most important steps in qualitative analysis are to select a sufficient amount of data in one time and to process the raw data (video interview) into coding (Dey 1993) before running it into Atlas.ti software for further analysis and results. 


\section{Result}

Using constant comparative analysis, data from interview and observation, resulted in several primary categories such as daily life challenges, vulnerability due to the urban flooding and finally the resilience towards flooding. These are presented in order below.

\subsection{Top daily life challenges}

One of the questions asked during the FGD was how the participants ranked their top daily life challenges including flooding. The results showed that most of the participants rank flooding as the least important challenge because for them, the floods only occur once a year when the northeast monsoon season passes by the east coast of Peninsular Malaysia. On the contrary, food supplies, health, education, economy and social issues are the top daily life challenges, respectively, as all these challenges are applicable on a daily basis. Hence, only when their environment is affected by flood, will it disturb their daily activities. Figure 3 shows the results for top daily life challenges faced by the participants and the comments on the challenges they faced.

The top daily challenges consist of seven elements: food, flood, health, education, economy, safety and social. The participants were expected to rank their top five daily challenges according to their priorities. Two sets of results were obtained and new challenges were added and discussed. Figure 4 shows the results of the two sets of daily life

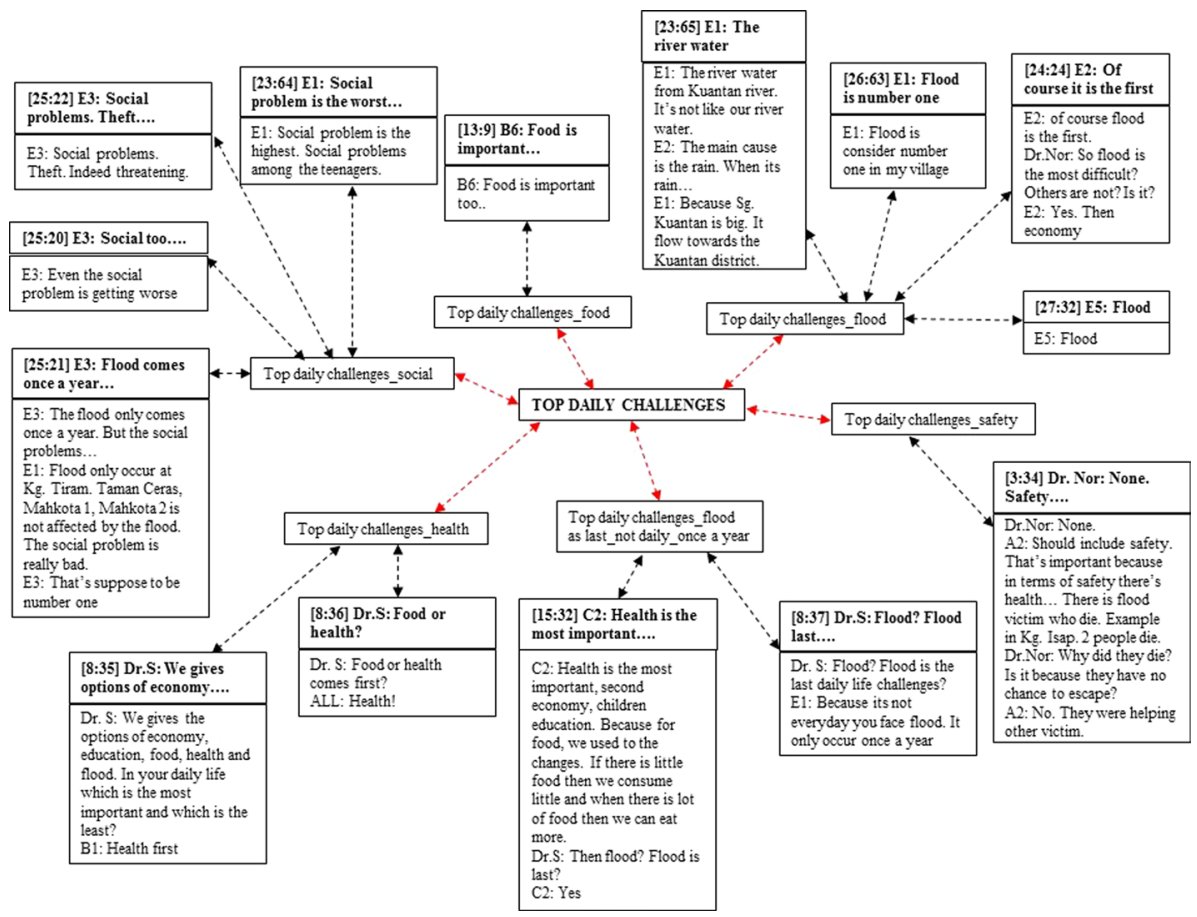

Fig. 3 Top daily life challenges ranked by the participants 


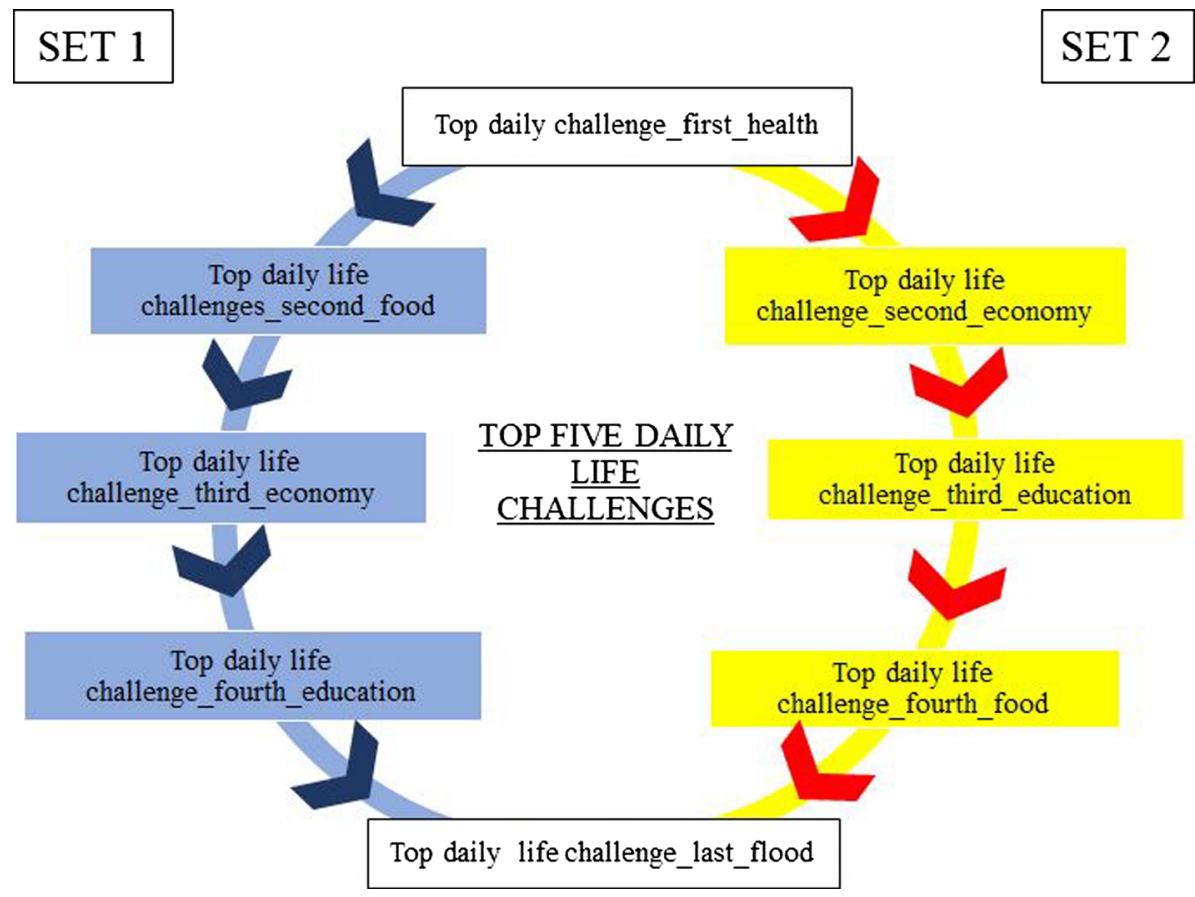

Fig. 4 Result of top daily life challenges ranked by the participants

challenges ranked by the participants. Social and safety were added in the discussion as additional challenges where the participant ascertains that it is important to be included.

Figure shows that from the two sets of results on the daily challenges, the first set shows that food is the priority while the flood was ranked last. However, in the second set of results some participants believed flooding should be ranked first. Those participants who ranked flood first live in areas that are seriously affected by the annual flood. Not only that, they also stated that the flooding event causes them hardships and disturbed their normal daily life. Conversely, those who ranked flood as their last priority in the daily challenges are from areas where the occurrence of flood is predictable and happens once a year; thus they have the opportunity to prepare beforehand. The constant occurrence and the signal given by the nature such as changes of the wind and cloud, and tidal water level at coastal and river basin help the victims to prepare themselves. Garai (2017) stated that understanding the sign and signal from the changes in nature has helped the people in the past to predict the upcoming flooding event. Moreover, technologies and experts from the meteorology department were able to predict and warn people about the upcoming event. Most of the participants ranked food first because it is important to have continuous supply for survival. Flooding will cause damages to most of the goods including foods. Food stalls, supermarket, mini markets and sundry shops will be closed down due to the flood. This will cause disruption in food supplies; hence, it is important to prepare and stock up the food supplies before the flood occurs. Equally important to food is health. For most of the participants, health is crucial. The impact of health from flooding comes in many forms. According to Rufat et al. (2015), one-third of the deaths during flood events occur away from the floodwater. Examples of deaths that can occur away from floodwater include deaths from 
dehydration, stroke, lack of medicine supplies and negligence of health issues prior to flood events (Jonkman et al. 2009).

Besides death, flooding can affect the mental health and psychology of a victim. The psychological effects are different according to anxiety and stress, age, gender, previous health condition and recovery duration, effects can usually acute after the event (Stanke et al. 2012). Other health issues such as water borne diseases due to contaminated water, malnutrition, fever and other infectious diseases are easily spread during and after the flood when the victims interact with each other at the transit centre. While discussing the top daily challenges, participants highlighted the importance of social and security issues. Social problems involving the teenagers and young adults usually increased. Most of the social problems that involve teenagers are vandalism, burglary and theft. Adger (1999) in his study stated that the actions displayed by the teenagers may be due to coping behaviour, stress or access to certain resources or needs. However, social problems are not limited to teenagers only. Adults who are also desperate took advantage from the flood event usually caused social problems. They usually break into the flood victim houses and steal any valuable goods such as electric appliance, jewelleries, car, motorcycles and even the house parts such as steels, wires and cable. This is when the social security elements from the discussion among the participants surfaced. Security in this context is not limited to assets and goods, but also the safety of individuals during the flood to avoid any casualties and death. Making sure all the important and valuable goods and assets are in a safe place before the flood occurred ensures the safety of the people's belongings. On the other hand, the security and safety of individuals during and after the flood is the top priority while it is encouraged to help those affected by flood, but not to the extent of risking their own life. For example, it is reported that there was a case of death at Kampung Isap where a man died due to drowning while trying to rescue another flood victim. Therefore, it is important to prioritize and take care of one's own life and safety during and after the flood events.

\subsection{Vulnerability}

This study investigated the vulnerability to flooding of the community of the study area. The results from the analysis are shown in Fig. 5. From the FGD, there are several reasons that cause the vulnerability to flooding in the community. Grounds and claims such as houses built near to the river banks and lowland areas, improper and ineffective flood evacuation plans, mismanagement of flood transit centres, lack of instant and accurate flood information and the lack of preparation for the flood by the community members have caused increases in the vulnerability of people to the flood event. Figure 5 shows that middle-aged participants ranging from 26 to 45 years old were concerned about the location of the housing area that can be easily affected by the flood, such as lowland area, near the river banks and swamp area. Meanwhile, the vulnerability of the older generation, from 56 to 65 years old, is mostly due to their refusal to stay at the transit centre, the type of their houses that are usually made from wood and the location of their houses which are mostly located near the beach that make it difficult for them to evacuate. In terms of income, for the participants with monthly income of less than RM1000 and less than RM3000, flooding has made them vulnerable and insecure. However, they refused to move to the transit centre as it may put their house at risk of burglary. Also, some of the transit centres are located far from their houses and some transit centres have imposed payment on the victims for shelter. For gender category, both males and females agree that uncertain flood warnings and warning issued only on 


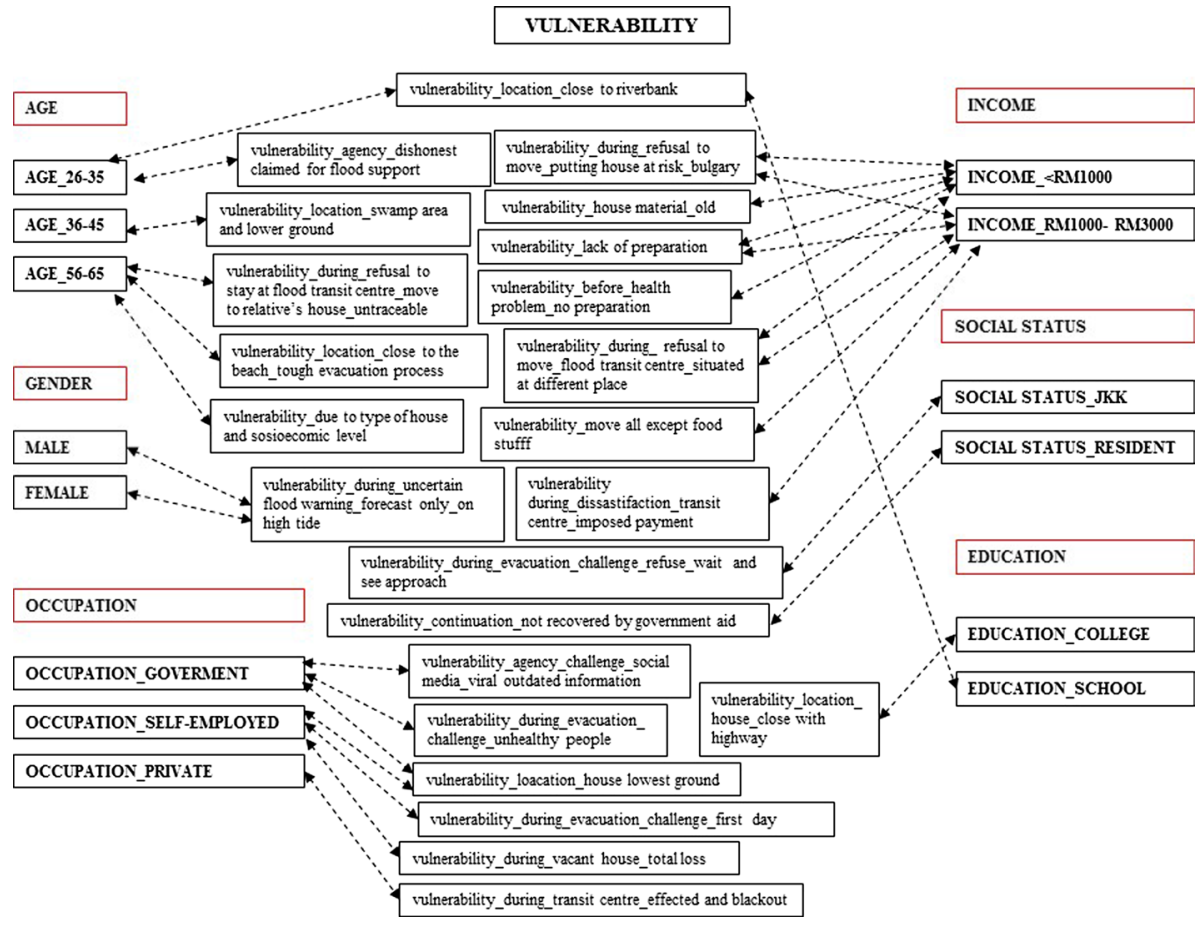

Fig. 5 The participants' flood vulnerability

high tides have caused them to be more vulnerable. The victims that are involved in the JKKK (village committee) have different vulnerability compared to the residents. The JKKK often faced problems during evacuation of other flood victims because most of them refused to be evacuated as they prefer to wait and see what unfolds. Different from the vulnerability faced by the JKKK committee, the residents are vulnerable towards the flood in terms of government aid that won't be enough to recover their damaged goods.

Victims with different education background seem to have made different choices about their house location, hence faced different vulnerability. Victims with high school education background mostly live near the riverbank which is more vulnerable, while those with college education background choose to live near the highways which can be easily accessed for an escape. Lastly, government, self-employment and private occupational victims have different aspect of vulnerability. Most of the victims that work with the government are more concerned on the accuracy of information circulated by the social media, the challenges in evacuation of sick victims and those whose houses are at low ground. As for self-employed victims, they are vulnerable because they can only afford houses situated on lower ground. They are more worried about losing their house and not having the ability to repair or build a new house. Evacuation is difficult because unlike the government and private sectors, they do not have holidays and have to work almost everyday. Those working in the private sector are more concerned about the condition of the transit centre during the flood. They are worried if the transit centre is not safe. All in all, in terms of health, most victims lack preparation for medicine and other basic medical facilities even before the flood occurs. 


\section{Discussion}

This study has examined aspects related to urban flooding in the study area. The main aspects are daily life challenges, vulnerability from the flooding, and the local future resilience towards floods. Everyone who was involved in the disaster will be impacted to some extent. Therefore, this study explores the response, reactions and the resilience of the victims before, during and after the event and why such behaviour and action were taken and displayed.

Vulnerability has been known as a leading tool to quantify and map human dimensions of hazards. The vulnerability of people to flooding is usually affected by variables such as income, ethnicity, education, age and gender. According to Rufat et al. (2015), income and poverty are the key drivers in vulnerability. Ajibade et al. (2013) think that women and children are more vulnerable compared to men because they are physically weaker than men and that the roles and responsibilities of women during flood event are more dangerous. The harder it is for someone to reconstruct their lives after the disastrous event, the more vulnerable they are. Contextual aspects of vulnerable populations obtained from the discussion are shown in Fig. 5. From the discussion, the vulnerability of the participants towards the flood can be grouped into geographical setting (location), socioeconomic, related agencies (societal network and insurance company) and the disaster's phase (during the flood). All the variables listed are the important keys to deconstruct vulnerability. Most of the vulnerability stated by the participants in the discussion is related to the location of the housing area. Houses located close to the riverbank, swamp and lowland area are vulnerable to the flood. This is because these areas can be easily flooded when the rivers overflow due to heavy rainfall and runoff from the higher area. Rapid urban development without consideration of the local housing area has also increased flooding. Intensity of the improper drainage systems and an imbalance in the embankment of lowland area for development has resulted in negative impacts on the locals, where local residences have to face unpredictable flood events caused by the embankment and incomplete drainage system designed by the developer. Moreover, the location of houses that are difficult to access, such as the beach area, hinder the process of evacuation and hence caused the victims to be vulnerable during the monsoon season. Meanwhile, the vulnerability in socioeconomic factors is measured through household income, poverty, unemployment, educational status and wealth (Rufat et al. 2015). According to Chan and Parker (1996), age and gender are related to income, those over 50 years of age have a comparatively low source of income. It is believed that income and poverty are the key drivers for vulnerability. According to Friend and Moench (2013), poverty and vulnerability are related but not the same; individuals with greater wealth experience are less vulnerable to flooding event. Therefore, since most of the victims in the study area have low income, the environment and housing conditions of the neighbourhood are poor. The material of the house is old and easily destroyed by flood and hence increased the vulnerability of the victims in the total loss of their house.

Nevertheless, the vulnerability in agencies such as insurance company and social network company is varied. For example, some of the victims may falsify claims towards the insurance agency for flood support. This is due to the shortage of money and funding necessary to get back to their daily life. Then, the vulnerability in social media towards the victims is because of the amount of outdated information that may lead to misunderstanding within groups of flood victims. The social media network needs to be sharp and alert in updating information regarding on the weather forecast from the meteorology stations. This is because most of the victims rely on the news they heard on TV, radio and even 
online social media for further actions. Finally, the victims are most vulnerable during the disaster phase. Some of the victims refused to stay at the flood transit centre because they are worried that their house may be at the risk of being robbed or the transit centre is situated a long way from their housing area. The risk perception that influences the vulnerability of the victims resulting in refusal to be transported to the transit centre is fear, uncertainty and worry of the safety of their family members, assets and properties (Willis et al. 2011). Nevertheless, the victims that faced a total loss of their house were evacuated to the transit centre for temporary shelter. Sometimes unexpected incidents such as black outs happened at the transit centre due to the electricity failure, which may cause trauma and panic attack to the flood victims at the transit centre where they do not feel safe and secure. For sick and elderly victims who are in wheel chairs, or others who are on machines and medical support, evacuation due to the flooding could be challenging, both for the victims and the evacuators. Furthermore, the uncertainties of flood warning and forecast caused them to be mentally tired all the time. In addition, some of the victims used the approach of 'wait and see'; hence they refused to be evacuated in the early phase of the flood. They will only evacuate when the situation worsens. This is a challenge to the volunteers. On the other hand, when the victims are evacuated, they are forced to leave their food stuff behind; therefore, they are depending solely on the food aid by the government at the transit centre. The continuous rain fall over a long period will caused the victims to be more vulnerable as more materials and properties will be damaged and destroyed by the floods and these will not be recovered by the government. Hence, more expenditure is needed to compensate their losses.

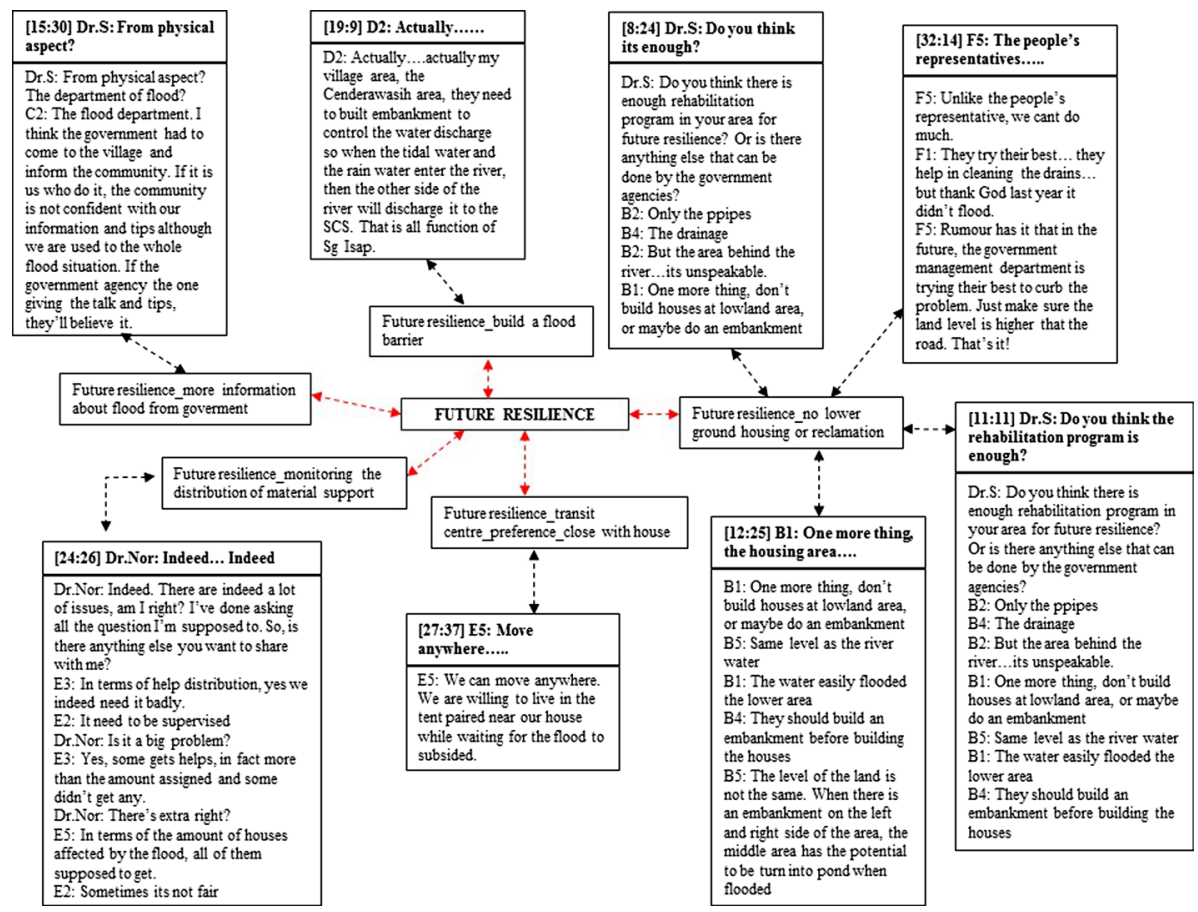

Fig. 6 The suggested future flood resilience 
Towards the end of the discussion, the participants were asked about their resilience towards flooding in the future. The results from the discussion can be seen in Fig. 6. Resilience is defined as the ability of a system to bear any commotion while sustaining certain levels of efficiency in its social, economic, physical and environment component (Balica and Wright 2010). There are several dimensions of resilience that have been highlighted by the participants such as the construction of flood barriers, information and updates on the flood, distribution of material support, transit centre and development on lowland. The participants acknowledged the present effort by relevant government agencies in helping and handling the flood hazard, but in their opinion, more can be done. The participant's perceptions regarding their resilience are that improvements need to be planned and supported by the government and other related agencies. By providing awareness programs for the public and information and updates on the flood situation, it helps the victims to understand more about flooding and hence help them in preparing and building resilience for future hazards. The participants also hoped that the authorities will be more sensitive to risk reduction including housing, infrastructure, utilities systems and regulation of land development according to the level of risk. In their opinion, there should not be any more development of lowland areas and the reclamation built by the developer need to be looked through of the side effects towards the present housing area. This is because some of the reclamation of land for new urban development areas has caused flooding to the present housing areas. The reclamation wall may accidentally block the water ways or the bypass for the overflow water to be discharged to the sea, thus causing unwanted and extreme flooding to the lowland area. The building of the water barrier has also caused the housing settlement between the barriers to be turned into a pond when overflow waters become stagnant in the middle of the lowland area. On the other hand, according to the participants, the distribution of the food aid given by the government to the victims needs to be supervised because there were cases where some of the victims were overlooked and they missed the aid that was distributed. Finally, the provision of community facilities such as evacuation centre, transit centres and temporary shelters is important in order to minimize residents' exposure to flood hazard. The participants stated that the victims preferred transit centres close to their houses. Public schools are typically used as evacuation grounds and temporary shelters during the disaster which are short in facilities, such as shower rooms. Victims are also worried about the cleanliness and hygiene of the public school. Developer and the state government are urged to build a proper transit centre for the victims to shelter where inadequacy of water and sanitary facilities should be the primary consideration. Therefore, the commitment and the involvement of government, NGO and urban dwellers in long-term flood management and risk will help in assisting the community in minimizing the damages resulted from the hazard; hence, they will manage to get back to their normal daily life in a short time.

\section{Conclusion}

All of the detail and genuine information on the vulnerability and the resilience of the floods from this study were obtained from the qualitative method called focus group discussion (FGD). The study was designed to capture the full range of perceptions on flooding from the urban community. The participants of the group discussion were volunteers who were interviewed for research purpose. Participants were divided into six groups with different demographic background for holistic results. The participants were willing to describe in detail the 
event, including their feelings and emotions towards the disaster. The information and data obtained are valuable and crucial to understanding the urban flood resilience and vulnerability theory and perceptions. Hence, it is equally important to take into consideration the response, actions and the reactions behind the participants' behaviour that were displayed. These will help in formulating future planning for effective flood hazard management.

The outcomes when the participants were asked to rank their top five daily challenges were obtained, and they showed that most felt that flooding is not the uppermost daily threat to them as the flood comes annually and is mostly predictable. The victims are most concerned with continuous food supply. Those who felt flood is a threat to them is due to the fact that they live in flood-prone areas. On the other hand, several participants believed that health is the most important variable in their daily life because without good health, they will not be able to work or execute their daily activities. After food and health, other challenges according to participants' priorities are education, economy, security and social. A large proportion of the population of the study area remains poor and vulnerable to floods, especially in the rural settlement. In other aspects, poor dissemination of early warning information and flood control infrastructures from the government and other related agencies have caused the victims to have little time to prepare for emergencies and hence cause the recovery process to be slower. Moreover, the housing location for most of the participants is within lowland areas which made them more vulnerable. Lowland areas are easily flooded due to heavy rainfall and tidal water from the South China Sea. Thus, it causes an abrupt increase in water volume that exceeds the river basin capacity. New development such as housing ranging from the hill to the valley is one of the major causes of increased flooding in the study area. What determines one's vulnerability is the gender roles, place, employment, health care, income and social status. The outcome shows that gender has no significance in determining vulnerability. Both male and females voiced concerns about the inefficiency in flood warning and forecasts issued by the government and media during the flood. Results also showed that participants with high or low income faced the same level of vulnerability. However, they refused to move to the designated flood transit centre due to the risk of their house being robbed and the location of the transit centre is far from their house. Notably, the low income victims were hit harder compared to the high income victims because they need more money and other sources of income in order to get back to their daily life. Lots of everyday appliances and goods need to be repaired or replaced which are costly to the poor. Therefore, in order to decrease the vulnerability due to the flooding event, resilience need be cultivated. A lesson should be learnt from the past event and actions should be taken to avoid losses. Structural and non-structural flood mitigation solutions should be taken and adapted to the flood-prone areas. A better flood prevention, mitigation response and rehabilitation should be implied in the disaster risk management.

Acknowledgements The authors would like to acknowledge the financial support provided by University of Malaya Research Grant under the Frontier Science Grant RG358-15AFR and Equitable Society Grant RP026B-15SBS, the engineers, assistance engineers and staff of Water Resources and Hydrology Unit, Drainage and Irrigation Department (DID), Kuantan, Pahang, Malaysia, the Kuantan District Officer, Kuantan Assistant District Officer, Penghulu Mukim (Headman) of Mukim Kuala Kuantan 1, staff of Kuantan District Office, Kuantan, Pahang and the Kuantan residents who have contributed in this article.

Open Access This article is licensed under a Creative Commons Attribution 4.0 International License, which permits use, sharing, adaptation, distribution and reproduction in any medium or format, as long as you give appropriate credit to the original author(s) and the source, provide a link to the Creative Commons licence, and indicate if changes were made. The images or other third party material in this article are included in the article's Creative Commons licence, unless indicated otherwise in a credit line to the material. If material is not included in the article's Creative Commons licence and your intended use is not 
permitted by statutory regulation or exceeds the permitted use, you will need to obtain permission directly from the copyright holder. To view a copy of this licence, visit http://creativecommons.org/licenses/by/4.0/.

\section{References}

Adger W (1999) Social vulnerability to climate change and extremes in coastal Vietnam. World Dev 27(2):249-269

Adger WN, Kelly PM, Winkels A, Huy LQ, Locke C (2006) Migration, remittances, livelihood trajectories, and social resilience. AMBIO J Hum Environ 31(4):358-366

Ajibade I, McBean G, Benzer-Kerr R (2013) Urban flooding in Lagos, Nigeria: patterns of vulnerability and resilience among women. Glob Environ Change 23:1714-1725

Balica S, Wright N (2010) Reducing the complexity of the flood vulnerability index. Environ Hazards 9(4):321-339

Bene C, Wood R, Newsham A, Davies M (2012) Resilience: new utopia or new tyranny? Reflection about the potentials and limits of the concept resilience in relation to vulnerability prograammes, IDS Working Paper 405. Institute of Development Studies, Brighton, Sussex

Berkes F, Colding J, Folke C (eds) (2003) Navigating social-ecological systems: building resilience for complexity and change. Cambridge University Press, Cambridge

Buckle P (2006) Assessing social resilience. In: Paton D, Johnston D (eds) Disaster resilience: an integrated approach, pp 88-103

Carpenter S, Walker B, Anderies J, Abel N (2001) From metaphor to measurement: resilience of what to what? Ecosystems 4:765-781

Chan NW (1997) Increasing Flood risk in Malaysia: causes and solutions. Disaster Prev Manag Int J 6(2): $1-16$

Chan NW (2012) Impacts of disasters and disasters risk management in Malaysia: the case of floods. In: Sawada Y, Oum S (eds) Economic and welfare impacts of disasters in East Asia and policy responses. ERIA Research Project Report 2011-8, Jakarta, pp 503-551

Chan NW (2015) Impacts of disasters and disaster risk management in Malaysia: the case of floods. In: Aldrich D, Oum S, Sawada Y (eds) Resilience and recovery in Asian disasters. Risk, governance and society, vol 18. Springer, Tokyo

Chan NW, Parker DJ (1996) Response to dynamic flood hazard factor in Peninsular Malaysia. Geogr J 162(3):313-325

Chia CW (1971) Managing flood problem in Malaysia. Bull Ing 38:38-43

De Bruijn KM (2004) Resilience indicators for flood risk management systems of lowland rivers. Int J River Basin Manag 2(3):199-210

Department of Irrigation and Drainage (DID) (2005) Annual flooding report of Pahang state 2005. Department of Irrigation and Drainage

Department of Irrigation and Drainage (DID) (2007) Fenomena Banjir Malaysia. Retrieved from http:// Www.Water.Gov.My/Images/Pdf/Fenomenabanjir_Msia.Pdf

Dey I (1993) Qualitative data analysis. A user-friendly guide for social scientists. Routledge, London

Dhar O, Nandargi S (2003) Hydro meteorological aspects of flood in India. Nat Hazard 28:1-33

Drainage and Irrigation Department (DID) (1988) Flood Forecasting and warning systems in Malaysia. Unpublished Paper of the Hydrological Section, Drainage and Irrigation Department, Ampang Branch

EKA (2002, July) Retrieved from global register of extreme flood events: http://www.dartmouth. edu/ floods/Archives/2001sum.htm

Folke C (2006) Resilience: the emergence of a perspective for social-ecological systems analyses. Glob Environ Change 16(3):253-267

Friend R, Moench M (2013) What is the purpose of urban climate resilience? Implications for addressing poverty and vulnerability. Urban Clim 6:98-113

Garai J (2017) Qualitative analysis of coping strategies of cyclone disaster in coastal area of Bangladesh. Nat Hazard 85:425

Godschalk D (2003) Urban hazard mitigation: creating resilient cities. Nat Hazard Rev 4:136-143

Green C, Turnstall S, Emery J, Bossman-Aggrey. P (1988) Evaluating the non-monetary impacts of flooding. Flood Hazard Research Centre, Enfield

Greenbaum T (2000) Moderating focus groups: a practical guide for group facilitation. Sage Publication, Thousand Oaks

Gunderson L (2000) Ecological resilience: in theory and application. Ann Rev Ecol Syst 31:425-439 
Holling CS (1973) Resilience and stability of ecological systems. Annu Rev Ecol Syst 4(1):1-23

Hussaini HA (2007) Flood and drought management in Malaysia. Ministry of Natural Resources and Environment, Kuala Lumpur

Hyden L, Bulow P (2003) Who's talking: drawing conclusions from focus groups-some methodological considerations. Int Soc Res Methodol 6(4):305-321

International Strategy for Disaster Reduction ISDR (2002) Annual report. Ministry of Natural Resources and Environment, Kuala Lumpur

Jackson J (2006) Fatal attraction: living with earthquakes, the growth of villages into megacities and earthquake vulnerability in the modern world. Philos Trans R Soc Lond A Math Phys Eng Sci 364:1911-1925

Jamaluddin M (1985) Flash flood problems and human responses to the flash flood hazard in Kuala Lumpur Area. Akademika 26:45-62

Jamaludin MH, Jaafar S, Chuah BK, Abdullah Z (2013) Flood: Kuantan Town Centre almost paralysed, 37,100 evacuated in 4 state. The News Straits Times Press, Berhad

James E (2008) Getting ahead of the next disaster: recent preparedness efforts in Indonesia. Dev Pract $18(3): 424-429$

Jonkman S, Maaskant EB, Levitan M (2009) Loss of life caused by the flooding of New Orleans after Hurricane Katrina: analysis of the relationship between flood characteristics and mortality. Risk Anal 20(5):676-698

Kithia J, Dowling R (2010) An integrated city-level planning process to address the impacts of climate change in Kenya: the case of Mombasa. Cities 27:466-475

Kitzinger J (1995) Introducing Focus Group. BMJ 311:299-302

Kruger R (1994) Focus Group: a practical guide for applied research. Sage Pubblications, Thousand Oaks

Lun PI, Gasim MB, Toriman ME, Rahim SA, Kamaruddin KA (2010) River flow conditions and dynamic state of Pahang River. In: Proceeding of the 2nd international conference on human habitat and environment. Putra Nilai, Negeri Sembilan, pp 617-633

Maykut P, Morehouse R (1994) Begining qualitative research. A philisophic and practical guide. Routledge, London

McCarthy JJ, Canziani OF, Leary NA, Dokken DJ, White KS (eds) (2001) Climate change 2001: impacts, adaptation and vulnerability. Cambridge University Press, Cambridge

Miles M, Huberman A (1994) Qualitative data analysis: an expanded sourcebook, 2nd edn. Sage, Thousand Oaks

Moench M (2009) Adapting to climate change and the risks associated with other natural hazards: methods for moving from concepts to action. In: Lisa E, Schipper F, Burton I (eds) The earthscan reader on adaptation to climate change. Earthscan, London, pp 249-280

Molua E, Lambi C (2007) The economic impact of climate change on agriculture in Cameroon. Policy Research Working Paper Series 4364, The World Bank

Norris FH, Stevens SP, Pfefferbaum B, Wyche KF, Pfefferbaum RL (2008) Community resilience as a metaphor, theory, set of capacities, and strategy for disaster readiness. Am J Commun Psychol 41:127-150

Proag V (2014) The concept of vulnerability and resilience. Procedia Econ Finance 18:369-376

Rufat S, Tate E, Burton CG, Maroof Abu Sayeed (2015) Social vulnerability to floods: Review of case studies and implications for measurement. Int J Disaster Risk Reduct 14:470-486

Saavedra C, Budd W (2009) Climate change and environmental planning: working to build community resilience and adaptive capacity in Washington State, USA. Habitat Int 33:246-252

Schwandt T (1997) Qualitative Inquiry. A dictionary of terms. Sage, London

Simon D (2007) Urbanisation and global environment change: new intergenerational challenges. Int J Green Econ 1(3-4):299-306

Small C, Nicholls J (2004) A global analysis of human settlement in coastal zones. Coast Res 19:584-599

Stanke C, Murray RA, Nurse J, Williams R (2012) The efffects of flooding on mental health: outcomes and recommendations from a review of the literature. Publ Libr Sci Curr Disaster 47:37

Suhaila J, Mohd Deni W, Zin Wan, Jemain AA (2010) Trends in Peninsular Malaysia rainfall data during Southwest monsoon and Northeast monsoon season. Sains Malays 39:533-542

Swyngedouw E, Heynen N (2003) Urban political ecology. Justice and the Politics scale. Antipode 35(5):898-918

Umar (2007) Disaster mitigation support and management in Malaysia. Retrieved from Malaysia Meteorological Department. www.met.gov.my/files/ClimateChange2007/session1a/. Accessed 16 May 2010

Williamson F (2016) The "Great Flood" of 1926: environmental change and post-disaster management in British Malaya. Ecosyst Health Sustain 2(11):1-9. https://doi.org/10.1002/ehs2.1248

Wills K, Natalier K, Revie M (2011) Understanding risk, choice and amenity in an urban area at risk of flooding. Hous Stud 26(2):225-239 
Publisher's Note Springer Nature remains neutral with regard to jurisdictional claims in published maps and institutional affiliations.

\section{Affiliations}

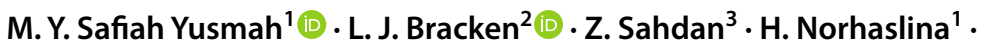

M. D. Melasutra ${ }^{4}$ A. Ghaffarianhoseini ${ }^{1}$ - S. Sumiliana ${ }^{5} \cdot$ A. S. Shereen Farisha ${ }^{1}$

1 Department of Geography, Faculty of Arts and Social Sciences, University Malaya, 50603 Kuala Lumpur, Malaysia

2 Institute of Hazard, Risk and Resilience, Durham University, Durham DH1 3LE, UK

3 Department of Geography and Environment, Universiti Pendidikan Sultan Idris, Tanjong Malim, 35900 Perak, Malaysia

4 Department of Urban Planning, Faculty of Architecture and Built Environment, University Malaya, 50603 Kuala Lumpur, Malaysia

5 Water Resources and Hydrology Unit, Drainage and Irrigation Department, Kuantan, Pahang, Malaysia 